\section{Glykoprotein, biliäres}

S. Holdenrieder ${ }^{1}$ und P. Stieber ${ }^{2}$

${ }^{1}$ Institut für Laboratoriumsmedizin, Deutsches Herzzentrum München, Klinik an der Technischen Universität München, München, Deutschland

${ }^{2}$ Institut für Laboratoriumsmedizin, Klinikum der Universität München (LMU), München, Deutschland

\section{Synonym(e) BGP; CD 66a}

Englischer Begriff biliary glycoprotein

Definition Das biliäre Glykoprotein ist ein Mitglied der CEA-Familie ( $\triangleright$ Carcinoembryonales Antigen), das in 7 verschiedenen Isoformen auftreten kann.

Struktur Bisher wurden 29 kodierende Gene der CEAFamilie beschrieben. 18 verschiedene Proteine werden exprimiert, wovon 7 der CEA-Subgruppe und 11 der „Pregnancyspecific glycoprotein-(PSG-)“Subgruppe angehören.

Das biliäre Glykoprotein ist zusammen mit dem CEA, dem „non-specific cross-reacting antigen“ (NCA) und den sogenannten „CEA gene family members“ (CGM) 1, 2, 6 und 7 ein Mitglied der Zellmembran-assoziierten CEA-Subgruppe. Es kann in 7 verschiedene Isoformen differenziert werden, die jeweils eine Homologie in der N-Region aufweisen.

Synthese - Verteilung - Abbau - Elimination Das biliäre Glykoprotein zeigt ein weniger selektives Expressionsmuster als CEA und wird von einer Reihe normaler Epithelien des Gastrointestinaltrakts einschließlich Ösophagus, Magen, Duodenum, Jejunum, Ileum, Kolon, Pankreas, Leber und Gallenblase sowie der Niere, Blase, Prostata, Zervix, Endometrium, in Schweiß- und Talgdrüsen, Granulozyten, Lymphozyten und in Endothelzellen einiger Organe gebildet.
Funktion - Pathophysiologie Das biliäre Glykoprotein hat ähnlich wie die anderen CEA-Subgruppenmitglieder zelladhärierende Eigenschaften und ist des Weiteren in der Signaltransduktion bzw. deren Regulation involviert.

Eine veränderte Expression des biliären Glykoproteins findet sich bei malignen Tumoren: Während sie bei Magen-, Bronchial-, Ovarial-, Endometriumkarzinom und bei der akuten lymphoblastischen Leukämie erhöht ist, wird bei kolorektalem und hepatozellulärem Karzinom eine erniedrigte Expression beschrieben.

Untersuchungsmaterial - Entnahmebedingungen Serum, Plasma, Galle.

Analytik $>$ Enzymimmunoassay (EIA), $\triangleright$ Immunradiometrischer Assay (IRMA).

Indikation Diagnostik und Verlaufskontrolle von Adenokarzinomen (durch CEA ersetzt).

Interpretation Aufgrund des im Vergleich zu CEA weniger selektiven Expressionsmusters wird in Diagnostik und Verlaufskontrolle von Tumorerkrankungen die Bestimmung des biliären Glykoprotein durch das spezifischere CEA ersetzt.

Diagnostische Wertigkeit Diagnostik und Verlaufskontrolle von Adenokarzinomen (durch CEA ersetzt).

\section{Literatur}

Hammarström S (1999) The carcinoembryonic antigen (CEA) family: structures, suggested functions and expression in normal and malignant tissues. Semin Cancer Biol 9:67-81 